\title{
Plantations and Basic Needs: The Changing International and National Setting
}

\section{Jürgen von Muralt and Jean-Paul Sajhau}

To describe and analyse the changing international and national setting of plantations and the extent to which they are able to satisfy the basic needs of the workers is almost impossible in a brief article - the situations and developments in different regions and countries are too diverse. This paper therefore aims to identify certain general trends using examples to illustrate developments, and to raise the main issues to be considered in an examination of the status of basic needs satisfaction in plantations. ${ }^{3}$ The article starts with a brief, but inconclusive discussion of the definition of plantations. It then outlines the major changes taking place in the plantation sectors of various countries. The second part is devoted to a brief description of the different elements which could constitute a basic needs approach.

\section{Controversies about Plantations}

Given the great importance plantations have in the national economy of many developing countries, as a source of foreign exchange, as a major employer in rural areas, as a provider of raw materials for industrial development or to supply consumer goods, it is astonishing that researchers interested in development issues have taken little notice of plantations as a distinct system for the production of certain agricultural commodities. When the General Report for the English Session of the ILO Committee on Work on Plantations, held in 1982, was prepared, a review of the existing literature revealed the lack of descriptive material and analytical research work on the role of plantations in development. When plantations were discussed it was usually in a rather emotional atmosphere and arguments - by both opponents and supporters of the plantation system - were often ideologically biased. Two brief quotations illustrate this point: 'The plantation system must be destroyed if the people of plantation society are to secure economic, social and psychological advancement' [Beckford 1972]. 'Plantation agriculture is superior to alternative agricultural systems for the production of tropical perennial crops' [Goldthorpe 1985].

\footnotetext{
1 A more detailed analysis of the plantation sector in a number of countries and further discussion of the issues raised in this paper will be found in a forthcoming ILO publication by the authors of this paper entitled Plantations and Plantation Workers.
}

One could argue that the second argument does not invalidate the first, since in spite of being an efficient and economically rational production system, plantations could nevertheless lead to the exploitation of people and stand in the way of developing a system of small-scale farms guaranteeing large-scale selfemployment, sufficient food production and social progress. The conditions under which plantations can effectively be integrated in an economic and social development policy and contribute to basic needs satisfaction of the rural poor need to be analysed in the light of the particular situation of a given country.

There is reason to suspect that the controversy about the role of plantations is due to some extent to the fact that different people have different views as to what plantations are. Indeed, it would appear difficult to come up with a working definition embracing all forms of agricultural enterprises which need to be considered in a discussion about the economic and social conditions of the people who work in those enterprises.

For example, when the ILO adopted in 1958 Convention No. 110 concerning Conditions of Employment of Plantation Workers, the following definition was used: 'any agricultural undertaking regularly employing hired workers which is situated in the tropical or subtropical regions and which is mainly concerned with the cultivation or production for commercial purposes of coffee, tea, sugarcane, rubber, bananas, cocoa, coconuts, groundnuts, cotton, tobacco, fibres (sisal, jute and hemp), citrus, palm oil, cinchona or pineapple; it does not include family or small-scale holdings producing for local consumption and not regularly employing hired workers'.

Although it is clear that this concept is still valid in broad terms, the scope of the definition adopted by the ILO was so wide that many countries found it impossible to ratify a Convention which would be difficult to implement in all cases. This is one major reason why, since 1958, only 11 countries (Brazil, Ivory Coast, Cuba, Ecuador, Guatemala, Liberia, Mexico, Nicaragua, Panama, Philippines, Uruguay) have ratified Convention No. 110, and of these two (Brazil and Liberia) denounced it afterwards. This poor level of ratification does not mean that the re is no specific legislation applicable to plantations or 
plantation workers. In a number of countries such legislation does exist, but the definition of plantations is much more restrictive. In India, for example, according to the Plantation Labour Act (1951) as amended in 1981, the word plantation covers any land used or intended to be used for growing tea, coffee, rubber, cinchona or cardamom which measures five hectares or more and in which 15 or more persons are employed or were employed on any day of the preceding 12 months.

As a result of the difficulties encountered in ratifying ILO Convention 110 , repeated calls were made for a revision and, in 1982, the International Labour Conference adopted a new Protocol to the Plantations Convention according to which a Member State may exclude from the application of the Convention 'undertakings the area of which covers not more than five hectares and which employ not more than ten workers at any time during a calendar year'. Following this revision, it is hoped that more countries will be better placed to revise their position vis-à-vis this Convention and proceed with ratification. In the Convention a flexibility clause is embodied which allows ratification step by step, i.e. certain parts of the Convention can initially be excluded from ratification.

\section{Food vs Export Crops}

The decline in food production and even serious food shortages in a number of countries has revived the long-standing debate about the appropriateness of maintaining a plantation sector which produces export crops, when insufficient food crops are grown for the population and large quantities of basic food items have to be imported. There are indeed situations where such basic conflicts can arise and where decisions need to be taken to ensure balanced agricultural development which takes into account the requirements for food production on the one hand and foreign exchange on the other. This is particularly acute when agricultural land and labour are scarce and there is competition for alternative uses. The problem may become severe when large areas of land are held by planters cultivating a single crop.

For example, the island of Negros in the Philippines is dominated by sugar plantations which, together with the sugar mills, are practically the only employers in the region. As a result of the low prices paid for sugar, which do not even cover production costs, there has been a steady deterioration in the economic position of the plantations, which in turn put a large percentage of the sugar workers out of their jobs. A rapid economic decline of the whole region followed. This resulted in serious hardship for the sugar workers who cannot find other employment and do not even have land on which to grow their own food. In order to preserve or even expand production of food crops and ensure self-sufficiency of small-holders growing typical plantation crops, in some countries upper limits have been fixed for the land on which those crops can be grown, as is the case in the tea sector of Kenya. Moreover, the evidence shows that countries which have been successful in expanding the production and export of plantation crops have sometimes also managed to increase their food crop production. But this may no longer be possible, especially given high rates of population growth and thus declining per capita food output.

\section{The Changing Features of Plantations}

The difficulty in defining plantations is also the result of the changing features of plantations over time. For the past 20 years, the ownership and production structures of plantations has been undergoing major changes and the traditional structures, if they still exist under the form of foreign enclaves, have lost their predominance and form only one type among many others.

New ownership structures have appeared, in particular with the increasing take-over of plantation units by nationals, through public and/or private interests. In some countries, political measures have been taken, very often after independence, which have led either to complete nationalisation of the plantation sector (for example in Cuba) or to partial nationalisation (such as the sisal plantations in Tanzania or the oil palm plantations in Benin). In other countries, such as Malaysia, national private interests have gradually bought out the foreign investors through purchases on the free market. At the same time, there has been a growing disinvestment process among multinational enterprises involved in the production of plantation crops to such an extent that in some countries they have completely disappeared. However, while multinationals disengaged from production activities, they maintained and in many cases reinforced their presence in the furnishing of inputs (supply of chemical products and of machinery) and in processing and marketing activities.

A number of factors have influenced this development: the political will in the major producing countries to take control over their national resources; the emergence of national economic groups with the financial capability of acquiring foreign interests; the strategy adopted by a number of multinational enterprises of withdrawing from activities subject to fluctuating and/or declining profitability and being increasingly controlled by host governments.

But it is interesting to see that, with a few exceptions, the change in ownership has not affected the basic production structure of the plantations, which continue to be run as large-scale commercial undertakings. Even countries which implemented rather stringent agrarian reforms limiting private ownership of agricultural land hardly changed the 
plantation system. India is a case in point, where plantations were exempted from land ceiling laws.

The second change which had an impact on plantations was growing government intervention. As mentioned before, in some cases governments took direct control over plantations through nationalisation or through the acquisition of the majority of assets, in other cases they acted as partners in joint ventures with foreign or local private capital. In recent years, however, many countries which nationalised the plantations sector have experienced difficulties, in particular due to managerial problems, and there is a new tendency among some of them (Tanzania, Benin, Mozambique) to try to attract private (national or foreign) investors again. Nevertheless, in almost all countries where there are plantations, the State has played an increasing role in the past 20 years by intervening indirectly to control, regulate, encourage and orientate activities in this sector. Using tax incentives and credit facilities, many governments have infuenced activities in the plantation sector in line with their development objectives, while at the same time facilitating the access of nationals to plantation ownership. They have also promoted the creation of cooperatives and the grouping of smallholders, and have set up in a number of cases government or parastatal agencies (like FELDA and RISDA in Malaysia or KTDA in Kenya) for this purpose. In some countries, in order to increase control of the markets for plantation crops, while at the same time guaranteeing more stable incomes for producers, governments have established Commodity Boards ('Caisses de Stabilisation')

However, it must be recognised that in several countries producers of export crops, be they large plantations or small farmers, receive prices for their produce which are well below those on international markets. Finally, most plantation countries have played an active part in all international negotiations aimed at stabilising prices and markets for plantation products, in particular through UNCTAD's Integrated Programme for Commodities or within the framework of the Lomé Conventions.

The 'new' structure of the plantation system is also characterised by the growing integration of smallgrowers. In a number of countries, with the help of the specialised agencies created by governments, smallholders have been able to penetrate the external markets for plantation crops. In this connection, one of the most successful experiences is the Kenyan Tea Development Authority, created in 1964 by the Government of Kenya with the support of the Commonwealth Development Corporation, with finance from the World Bank, OPEC and the European Economic Community. In roughly two decades KTDA organised the planting of more than 50,000 hectares of tea by 140,000 smallholders. As a result, smallholder tea exports, virtually non-existent before 1960, have accounted for about one third of Kenya's annual tea exports since the mid 1970s. In other cases, the impetus for smallholders' expansion has been given by large plantations, which, with or without the support of governments, have provided financial, technological or training assistance to smallholders. In Southern India, for example, since 1970 the major planters' association, UPASI (United Planters Association of Southern India), has undertaken a joint programme with the Tea Board of India providing technical assistance to small planters. A training programme has thus been implemented and already benefited 2,500 smallholders, while selected plants were offered at subsidised prices.

Another important development concerns the creation of 'nucleus estates'. In this production system, large plantations favour the expansion around the estates of smallholdings managed by individual farmers. These mini estates benefit generally from technical assistance, receive financial support to start their activities, and are able to use the infrastructure (including the processing facilities) created by large plantations. In Indonesia, for example, it is through the Nucleus Estates Smallholders' Programme that small growers have entered the palm-oil market and have increased their participation in the tea market. In the Ivory Coast these smallholdings, called 'Plantations Villageoises', are expanding around the large industrial complexes created by the government for the exploitation of rubber and palm-oil.

Finally, attempts are being made in many developing countries to diversify and/or reorientate output in order to reduce the vulnerability of the plantation sector in a fluctuating and often unfavourable international environment. Thus a number of countries heavily dependent on a single crop have encouraged diversification into other crops which seemed more profitable. In the Philippines, for example, the government endeavoured to introduce non-traditional export crops like bananas, pineapples and coffee into a plantation sector highly dominated by sugar cane and coconuts. However, in spite of the good results achieved, the Philippine economy was severely hit by the sugar crisis in 1985. In other cases, the priorities among plantation crops changed. In Malaysia, for example, during the 1960s and early 1970s, there was an important shift from rubber towards palm-oil. In the early 1980s, however, following the oil shocks of the 1970s, the Malaysian authorities began to think that the competitive position of synthetic rubber would continue to decline and that natural rubber could have a better future than palm-oil, so rubber recovered its leading role in the economy.

In spite of these policies a large number of developing countries are still heavily dependent on a limited 
number of plantation crops. This dependence is not only felt by the country as a whole, in terms of fluctuating foreign exchange earnings, but more directly by those who own and operate plantations. The trend of depressed world market prices for most plantation crops over the past 10 years has led to deteriorating terms of trade given the constant increase in prices of inputs, mostly imported. Since direct labour costs for permanent staff could hardly be reduced, plantation enterprises are aiming at increasing productivity and at the same time, attempting to lower the indirect cost of labour. The change for permanent to seasonal or even casual labour is becoming one of the main means of cutting costs. Costs not directly related to production are also being kept low, and often investments and operating costs for social and welfare facilities are critically reviewed. It is obvious that such a policy, wherever pursued, also affects the level of the provision of goods and services for the satisfaction of basic needs.

\section{Satisfying Basic Needs in the Plantation Sector}

In 1976, the ILO's World Employment Conference adopted a Declaration of Principles and a Programme of Action which endorsed the basic needs approach to development in the following words:

strategies and national development plans and policies should include explicitly, as a priority objective, the promotion of employment and the satisfaction of the basic needs of each country's population. The concept of basic needs, as understood in this Conference, includes two elements. First, it includes certain minimum requirements of a family for private consumption: adequate food, shelter and clothing as well as certain household equipment and furniture. Second, it includes essential services provided by and for the community at large, such as safe drinking water, sanitation, transport, health, educational and cultural facilities.

For plantation workers, this approach is of particular importance, as they traditionally reside with their families on estates which are often located far from inhabited centres. Thus, the satisfaction of basic needs of plantation workers requires the provision of special facilities linked to the environment in which they work and live. Owners and managers of plantations realised very early that they would have to provide their workforce with specific infrastructures and social benefits so that even at the time of forced labour, they organised the supply of housing, medical care and food, if only with the objective of maintaining a high level of productivity of their 'human capital'. Later on, with the increased involvement of trade unions and governments in industrial relations, and probably also as a result of the activities undertaken by some international organisations such as the ILO, 'decent living conditions' became an element of employers' personnel policy, especially since at the same time they were experiencing difficulties in recruiting and maintaining their labour force on the estates.

\section{Housing and Shelter}

In any economic activity, a worker's efficiency, health and quality of life in general depend to a large extent on the conditions in which $\mathrm{s} / \mathrm{he}$ is housed. In the case of plantations, this dependence is particularly strong, since plantations constitute a closed entity where, generally, the workplace and the place of residence are the same. The provision of adequate housing is, in consequence, an essential element contributing to the satisfaction of basic needs.

At the initial stage of their operations, planters usually provided housing facilities for their labour force; however, the quality of such housing was often criticised and initiatives were launched at national and international levels to improve the situation. In a number of countries, including Ivory Coast, Kenya, the Central African Republic, Nigeria, Mauritius, Tanzania, Argentina, Colombia, Honduras, Mexico, Papua New Guinea, Bangladesh, India, and Sri Lanka the labour legislation applicable to plantation workers stipulates that employers should provide housing for their workers. In other countries, particularly in Asia (Malaysia, the Philippines), although there is no legal obligation, there is a tradition among plantation owners to provide housing facilities to their workers and their families.

But while the practice of offering housing facilities on plantations may be widespread, much remains to be said about the quality of this housing. In their answers to the questionnaire sent by the ILO for the preparation of the Eighth Session of the Committee on Work on Plantations, a number of governments indicated that houses provided by employers were not always adequate and sometimes fell below legal minimum standards. Due to a number of factors, including economic difficulties, employers were unable or unwilling to comply with the law. For example, in the case of Tanzania, it was indicated that because of economic difficulties, houses provided by employers were not adequate for all families working in plantations. In Bangladesh, despite recent efforts, housing conditions on plantations remain poor (the majority of houses were built from mud, bamboo and thatch) and some employers evade their legal obligations by providing their employees only with a piece of land on which they have to put up their own home. In Sri Lanka, the type of housing provided leaves much to be desired, some of the houses having been built almost a century ago. Even in India, where the legislation applicable to plantation workers is very 
detailed and housing provisions well specified, a recent study undertaken by the Federal Government concerning Southern India concluded that there was a housing shortage on plantations and that a significant number of houses were sub-standard with, for example, only one room or inadequate sanitary facilities (Government of India 1984).

The same situation applies in a number of Central American countries and in the Caribbean. A Commission of Inquiry appointed by the ILO to examine the observance of certain International Labour Conventions by the Dominican Republic, with respect to the employment of Haitian workers recruited to work on sugar plantations, concluded that the housing situation of cane cutters living in camps known as bateys was inadequate, houses had poor sanitary facilities, and, in almost all cases, no electricity and no piped water [ILO 1983]. In Latin America where, in general, housing conditions are satisfactory, housing legislation is normally only applicable to permanent workers, while seasonal workers tend to constitute the bulk of the labour force, particularly in sugarcane plantations.

The growing importance of seasonal work is not limited to Latin America, and this new phenomenon creates additional problems as seasonal workers are less protected by legislation or collective agreements and thus do not benefit from the advantages conceded to permanent workers, particularly in terms of housing.

\section{Health and Medical Care}

A second important element of welfare concerns medical care facilities and the associated health issues. As in the case of housing, the responsibility for the organisation of free medical services on plantations fell traditionally on the employer, and the situation has remained largely unchanged. In the majority of countries, large plantations provide free or subsidised medical facilities to their permanent workers and often they are obliged by law to do so. Depending on the country, the state of the medical infrastructure and the distance of the plantation from public medical centres, the employers' obligations range from the provision of a first-aid kit to the construction of bush hospitals equipped to perform relatively complex medical operations (as in India), though the most common requirement is to build a dispensary. The quality of the services provided varies considerably from country to country and from plantation to plantation (the best situation is usually found in large plantations); a regular supply of adequate medicine is not always assured and in a number of cases there is a shortage of qualified personnel. Among dispensaries the principle of 'visiting doctors' is generally the rule and the permanent staff is usually very limited and sometimes unqualified. In addition, the protection of seasonal workers is not guaranteed in all cases and the provision of medical services is often limited to permanent workers. As a result, health conditions on plantations are worrying. In view of the location of plantations in the tropical and sub-tropical areas, major sicknesses are caused by tropical diseases, but other health problems are frequently encountered due to inadequate sanitary and housing facilities and malnutrition syndromes. In fact, it has been critically remarked that while curative medical care may be reasonably well organised, little or nothing is being done about prevention through, for example, improving sanitary conditions.

\section{Occupational Hazards}

The risks associated with the work on plantations vary according to the type of job performed and the type of plantation. However, a number of common factors may lead to accidents. On all plantations, a number of accidents are due to encounters with animals (reptiles, insects and wild animals), while exposure to the elements (cold and wind in tea plantations, or prolonged exposure to the sun) is another cause of ill-health or accidents. The development of mechanisation in a number of field activities has also created new risks associated with the running and maintenance of machinery. Finally, a major hazard facing plantation workers stems from the increasing use of various chemical substances (mainly pesticides and fertilisers) possessing toxic properties. An increasing number of cases of poisoning due to the use of chemicals are registered every year, which indicates that the conditions required for their safe use are not always met.

An essential pre-requisite for the implementation of effective measures to modify the living and working environment would be the elaboration of an appropriate data bank and information system. Unfortunately, until now, information on occupational mortality, like that on non-occupational mortality, has remained poor.

\section{Food Supply}

The supply of food, which is also important due to the often isolated location of plantations, has been organised in different ways. Originally, company stores owned by the plantation owners were created, and they are still fairly common in Latin America. Unfortunately, the company store system has been abused, especially where the responsibility for the stores was given to outside private storekeepers inadequately supervised by the management and not controlled by trade unions. Under the pressure of trade unions, a number of governments has facilitated the creation of cooperatives for the production and sale of basic commoditites, and legal provisions have been adopted requiring plantations to make land available to workers for their private use (to grow food crops). The practice whereby employers (particularly 
in Africa and some Asian countries) distributed free daily food rations has gradually been abandoned and replaced by more selective distribution of basic commodities. In Bangladesh, subsidised food entitlements for plantation workers still constitute an important component of the total remuneration package. Finally, when the national food situation has been particularly difficult, international bodies (such as the World Food Programme) have been requested to provide assistance, especially within the framework of rehabilitation programmes.

\section{Basic Education and Child Care}

It has always been a tradition, among larger plantations, to set up primary schools and crèches for the workers' children, as these two elements were part of the normal package of welfare facilities offered to permanent workers. However, the conditions under which educational schemes are usually implemented are far from satisfactory, though in some instances they compare favourably with the educational facilities existing in rural areas. Plantation schools often suffer from a shortage of teaching staff and teaching material and there is a high rate of absenteeism, particularly during the harvest when all available hands are needed. The availability of crèches is, on the other hand, gaining in importance since more and more women are entering the paid workforce. Improvements have been made in this field but financial resources are often too limited to meet the need. Only the largest and best organised plantations have hygienic, properly equipped crèches staffed by sufficient numbers of trained personnel, though even here crèches can encourage the practice of inadequate bottle-feeding, leading to undernutrition and disease.

\section{Wages and Remuneration}

The importance of the changes which occurred in the structures of plantations might lead one to expect substantial changes in workers' living conditions. The fact of the matter is, however, that current living conditions on plantations are in many respects much the same as they were 20 or 30 years ago. One might also have expected that wages would have been substantially improved with the growing control of nationals over the sector. In fact the situation improved somewhat with the gradual extension of minimum wage legislation applicable to rural, including plantation, workers which protected them against a number of abuses and favoured the development of remuneration systems combining time and piece rates, thus guaranteeing a minimum income. While minimum wages initially afforded some protection to plantation workers, and agricultural workers generally, in a number of countries their very existence limited the possibilities for wage increases. Only where plantation workers succeeded in establishing strong trade unions could better wages be negotiated. The development of trade union organisations of plantation workers has certainly contributed to raising wage levels above those existing in the nonorganised agricultural sector.

Wages of seasonal workers who are usually employed only for relatively short periods, mostly during harvest, are almost always based on piece rates and thus compare well with the wages paid to permanent workers. But these seasonal workers do not normally enjoy the non-wage benefits of permanent workers such as free housing, education or food rations.

\section{Conclusions}

It would appear as if things are not so bad after all and plantation workers, at least the permanent ones, enjoy employment and working conditions which compare favourably with those of landless agricultural labourers. The price paid for stable employment and certain basic amenities, however, is total dependence on the plantations and the absence of freedom of movement and choice of employment. Any comparison between wage levels in agriculture, plantations and the industrial sector (which would in many instances show a widening gap in favour of industrial workers) needs to be considered with caution, particularly in view of the existence of non-monetary benefits received by the plantation workers, which reduce the gap in cash wages.

While as a rule industrial wages are determined through collective agreements, plantation wages are still often fixed on the basis of minimum wage rates applicable to agricultural work and providing only a subsistence income. But it is difficult to generalise. The situation varies from country to country and even from plantation to plantation. Workers on South Indian tea plantations are relatively well off, while in Tanzania, for example, sisal estates cannot find workers because of the unattractive employment and working conditions.

There can be no doubt that plantations constitute an economically rational form of agricultural enterprise which many countries depend upon for a number of reasons. What is needed would seem to be better knowledge of the specific characteristics these plantations have in a given situation, the socioeconomic environment in which they operate, their prospensity to integrate in the development process and even to act as a stimulant to general rural development. 